\title{
Neonatal Gastric Perforation
}

\author{
Islam ADMS ${ }^{1}$, Aziz $\mathrm{MA}^{2}$, Shahjahan $\mathrm{M}^{3}$, Ali MA ${ }^{4}$
}

\begin{abstract}
Introduction: Neonatal Gastric Perforation is a rare but life threatening condition. Its incidence is reportedly to be 1 in 5000 live births. In most cases, the underlying cause could not be precisely determined. Prematurity, low birth weight, mechanical stress, and male gender are important factors.
\end{abstract}

Objectives: The objective of this study is to share the experience of neonatal gastric perforation in Dhaka Shishu Hospital with regard to etiology, clinical presentation and surgical outcome.

Materials and Methods: This retrospective study of seven neonates with Gastric Perforation was carried out at Dhaka Shishu Hospital from July 2008 to June 2011. The data reviewed included birth weight, gestational age at birth, age at presentation, clinical manifestations, pathological findings and outcome.

Results: There were 5 male and 2 female neonates among them 3 were mature and 4 were premature. The average birth weight was $2.67 \mathrm{~kg}$. Associated anomalies were present in 2 neonates $(28.57 \%$ ). Four patients had perforations in the greater curvature of stomach (57.14\%), 2 in the anterior wall $(28.57 \%)$, and 1 in the posterior wall $(14.28 \%)$. The overall mortality in our series was $57.14 \%$. The overall mortality of reported series was $48.91 \%$. Among them thirty three were premature with $75.75 \%$ mortality, and 59 were term neonates with $33.89 \%$ mortality.

Conclusion: Premature and low birth weight neonates are at increased risk of gastric perforation as well as mortality from it.

Key-words: Neonatal, Gastric Perforation, Prematurity, Low birth weight.

\section{Introduction}

Neonatal Gastric Perforation is rare but life threatening condition. It often occurs without any apparent precipitating event, after which patients deteriorate rapidly ${ }^{1}$. Its incidence is reportedly to be 1 in 5000 live births ${ }^{2}$. Gastric perforation constitutes $7 \%$ of all gastrointestinal perforation ${ }^{3}$. Sidebold ${ }^{4}$ first reported a case of Neonatal spontaneous Gastric Perforation in 1825. The first successful surgical repair was reported by Leger et $\mathrm{al}^{5}$ in 1950 , and several subsequent reports of successful repair have been reported and improved survival rates have been documented ${ }^{6,7}$. In most cases, the underlying cause could not be precisely determined. Prematurity is a facilitating factor ${ }^{8}$. Some mechanical factors are also considered as risk factor (i.e. the mechanical pressure by nasogastric or orogastric catheters, excessive gastric distension due to positive pressure ventilation $)^{8}$. Male gender has been suggested to be poor prognostic factor for survival ${ }^{1}$.

Good surgical outcome could be achieved by early diagnosis, resuscitation and early surgical intervention. Despite every effort mortality in this entity is very high ${ }^{9}$ ranging from $27-83 \%$. Being the rare entity there is paucity of local literature regarding neonatal gastric perforation. The aim of this study was to share the experience of neonatal gastric perforation in Dhaka Shishu Hospital with regard to etiology, clinical presentation and surgical outcome.

\section{Materials and Methods}

Seven neonates with gastric perforation were admitted in Dhaka Shishu Hospital from July 2008 to June 2011, and their records were retrospectively analyzed. Gastric perforation was diagnosed at operation. The data reviewed included birth weight, gestational age at birth, age at presentation, clinical manifestations, pathological findings and outcome.

1. Lt Col Abu Daud Md Shariful Islam, MBBS, FCPS(Surgery), FCPS(Paedatric Surgery), CMH, Dhaka; 2. Prof Md Abdul Aziz, MBBS, MS, Professor of Paediatric Surgery, Dhaka Shishu Hospital, Dhaka; 3. Dr. Md Shahjahan, MBBS, MS, Medical Officer, Dhaka Shishu Hospital, Dhaka; 4. Dr. Md Ayub Ali, MBBS, Medical Officer, Dhaka Shishu Hospital, Dhaka. 
Newborns with clinical findings suggestive of surgical abdomen underwent plain X-ray abdomen. With X-ray findings of gastrointestinal perforation all the patients had pre-operative resuscitation. Primary closure of perforation after debridement of dead tissue and peritoneal lavage with warm saline and placement of drain were opted in all patients. Statistical analysis was done using SPSS. A P value $<0.05$ was considered to be statistically significant.

\section{Results}

Seven patients, 5 males and 2 females, with malefemale ratio of 2.5: 1 were included in the study. All the patients were treated at the same hospital, among them 3 were full term and 4 were pre-term neonates. The clinical data are summarized in Table-l. The average birth weight was $2.67 \mathrm{~kg}$ (range, $2.1-3.5 \mathrm{~kg}$ ).

Table-I: Clinical data of neonates with gastric perforation $(n=7)$.

\begin{tabular}{|l|c|c|c|c|c|c|c|}
\hline Parameter & Case 1 & Case 2 & Case 3 & Case 4 & Case 5 & Case 6 & Case \\
\hline Sex & M & F & M & M & M & F & M \\
\hline Gestational age(Week) & 33 & T & 34 & T & 35 & 34 & T \\
\hline Birth weight (kg) & 2.1 & 3.5 & 2.4 & 3.0 & 2.4 & 2.2 & 3.0 \\
\hline Age at Presentation (day) & 7 & 4 & 2 & 3 & 4 & 5 & 3 \\
\hline Associated anomaly & - & - & Ileal atresia & - & - & CHD & - \\
\hline Location of perforation & Post wall & G curv & Ant wall & G curv & G curv & Ant wall & G cur \\
\hline surgery & P & P & B & P & P & P & P \\
\hline Outcome & D & S & D & S & D & D & S \\
\hline
\end{tabular}

$\mathrm{M}=$ Male, $\mathrm{F}=$ Female, $\mathrm{T}=$ Term,$-=$ None, $\mathrm{CHD}=$ Congenital Heart Disease, $G$ curv = Greater curvature of stomach, Post wall = Posterior wall, Ant wall $=$ Anterior wall, $\mathrm{P}=$ Primary repair, $\mathrm{B}=$ Primary repair with partial Bowel resection, $D=$ Died, $S=$ Survived.

The most common presenting manifestations include poor activity, abdominal distension, and respiratory distress (Table-II). Associated anomalies were found in two patients. In case number 3 , during exploratory laparotomy ileal atresia type- 1 was revealed and managed accordingly. In case number 6 , during resuscitation and workup it was diagnosed having congenital heart disease (Atrial Septal Defect). This patient died in post-operative period. The day of presentation varied from 2 days to 7 days after birth.

Table-Il: Initial manifestations of neonates with gastric perforation $(n=7)$.

\begin{tabular}{|l|c|}
\hline Status & n (Percentage) \\
\hline Poor activity & $7(100 \%)$ \\
\hline Abdominal distension & $7(100 \%)$ \\
\hline Respiratory distress & $5(71.42 \%)$ \\
\hline Features of Septicaemia & $3(42.85 \%)$ \\
\hline
\end{tabular}

Massive pneumoperitoneum was a consistent radiographic finding, leading to a pre-operative diagnosis of perforated hollow viscus. After resuscitation all patients underwent laparotomy. Four patients had perforations in the greater curvature of stomach (57.14\%), 2 in the anterior wall $(28.57 \%)$, and 1 in the posterior wall $(14.28 \%)$. Simple primary repair was done in six cases and partial bowel resection with primary repair in 1 case. The overall mortality in our series was $57.14 \%$ (4/7). In premature and low birth weight babies it was $75 \%$ (3/4) (P 0.37) (Table-III).

Table-III: Prognostic factors of neonates with gastric perforation $(n=7)$.

\begin{tabular}{|l|c|c|c|}
\hline & Survival $(\mathrm{n}=3)$ & Non survival $(\mathrm{n}=4)$ & $\mathrm{p}^{*}$ \\
\hline Male & 2 & 2 & 0.32 \\
\hline Low birth weight & 1 & 3 & 0.37 \\
\hline Prematurity & 1 & 3 & 0.37 \\
\hline
\end{tabular}

${ }^{*}$ Fishers exact test, one-tailed.

\section{Discussion}

Neonatal Gastric Perforation is a rare surgical emergency associated with high morbidity and mortality $^{8}$. It is higher in black than white and at least four times higher in male than female ${ }^{10}$ while in the study male to female ratio was $2.5: 1$. The etiology of neonatal gastric perforation is still unclear. Several possibilities have been discussed, including traumatic, ischaemic and spontaneous ${ }^{9,11}$. In 1996, Grosfeld JL et al reported 7 out of 16 cases of gastric perforations were caused by iatrogenic trauma either due to vigorous nasogastric or orogastric tube placement or due to positive pressure ventilation or bag mask resuscitation ${ }^{12}$. None of the case in this study, had traumatic perforation. Ischaemic gastric perforation mechanism has not been fully understood because it is associated with conditions causing severe physiological stress in neonate: hypoxia, prematurity and sepsis ${ }^{13,14}$. It has also been reported in necrotizing enterocolitis. High gastric acid secretions in 2nd day of life and stress ulcers in the critically ill patients were also reported and they are supposed to cause perforation due to trans-mural necrosis of these ulcers ${ }^{15}$. In this study, there were four preterm neonates, perforation in these cases may be due to this entity, but none had enterocolitis. Twenty percent cases are not related to any underlying risk factor are considered as spontaneous/ idiopathic ${ }^{16}$. The reported incidence of spontaneous perforation was 1 in 2900 live births ${ }^{17}$. A number of theories have 
been suggested to explain the causes in spontaneous gastric perforation including; congenital absence of muscularis mucosae in the greater curvature of stomach ${ }^{18}$, non-communication of right and left gastro-epiploic arteries causing localized ischemia leading to perforation at greater curvature $^{19}$. Pneumatic dilatation of stomach due to incoordination or immaturity of vomiting mechanism in infants causing increase in intragastric pressure during vomiting also cause gastric perforation ${ }^{20}$. Recent study showed that, absence/ lack of Cajal cells is one of the risk factor for spontaneous gastric perforation $^{21}$. In this study, it could be assumed that some of the cases had spontaneous gastric perforation.

The peak incidence of gastric perforation is reported to be from the 2 nd to 7 th day of life ${ }^{22,23}$ similar to that observed in this series. Miller ${ }^{24}$ found that gastric acidity in the new born child was equal to that of an adult and was maximal at 24 hours of age. The acidity decrease over the following 9 days by which point it approached the normal level of a child ${ }^{24}$. Thus, the gastric acidity is exceptionally high during the first week of life, which is the period in which the incidence of gastric perforation peaks. While this temporal association does not prove causality, it is possible that high gastric acidity in the early newborn period contributes to gastric perforation. Clinical features of gastric perforation are those of acute abdomen. The poor activity and abdominal distension were the most common findings which is the same as described by Chung et $\mathrm{al}^{23}$. Severity of respiratory distress depends upon the distension of abdomen and the maturity of the neonate. In this study, it was observed in $71.42 \%$ of the patients which is almost the same as shown by Chung et $\mathrm{al}^{23}$. Septicaemia was a pertinent finding and main cause of death suggested by other studies ${ }^{19}$. In this series, it was $42.85 \%$. Gastric perforation generally occurs in the fundus and greater curvature of the stomach. It has been found that $57.14 \%$ of perforation was at greater curvature, and $28.57 \%$ was at the anterior wall of stomach. It is similar to other studies ${ }^{8}$. Despite advances in peri-operative management Kara et al ${ }^{17}$ and Durhan et al ${ }^{8}$ reported high mortality. Lin LM et al ${ }^{1}$ showed overall mortality was $47 \%$, with significantly higher (83\%) in premature babies. In this series, overall mortality was $57.14 \%$ and for premature neonate it was $75 \%$.
Degree of maturity, low birth weight, hypoxia, peritoneal contamination, and duration of illness are risk factors for mortality. Preterm babies are more prone to respiratory distress and Septicaemia and leading to very high mortality. Septicaemia was the main killer in this series. For improvement in survival rate in patients with neonatal gastric perforation early diagnosis, timely surgery and proper pre and post-operative management need skilled staff and modern facilities. There is a controversy that spontaneous neonatal gastric perforation is an old concept and it is always associated with some pathology ${ }^{21}$. In this study, no association with primary pathology was found. So, we support the concept of spontaneous gastric perforation as suggested by Kara et $\mathrm{al}^{17}$.

\section{Conclusion}

Prominent feature in this study were prematurity and low birth weight. These neonates are at increased risk of gastric perforation as well as mortality from it. So, they should be managed cautiously.

\section{References}

1. Lin CM, Lee HC, Kao HA et al. Neonatal Gastric Perforation: Report of 15 cases and Review of the literature. Pediatr Neonatol 2008; 49(3): 65-70.

2. Jawad AJ, Al-Rabie A, Hadi A et al. Spontaneous Neonatal Gastric perforation. Pediatr Surg Int 2002; 18: 396-9.

3. Attridge JT, Clerk R, Walker MW et al. New Insights into spontaneous intestinal perforations using a national data set: Two populations of patients with perforation. J Perinatol 2006; 26: 185-8.

4. Wilson ES Jr. Neonatal Gastric Perforation. Am J Roentgenol Radium Ther Nucl Med 1968; 103: 307-9.

5. Reams GB, Dunaway JB, Wall WL. Neonatal Gastric Perforation with survival. Pediatrics 1963; 31: 97-102.

6. Leone RJ Jr, Krasna IH. Spontaneous Neonatal Gastric perforation: Is it really spontaneous? J Pediatr Surg 2000; 35: 1066-9.

7. Kieswetter WB. Spontaneous rupture of the stomach in the newborn. Am J Dis Child 1956; 91: 162-7.

8. Duran $R$, Inan $M$, Vatansever $U$ et al. Etiology of neonatal gastric perforation: Review of 10 years experience. Pediatr Int 2007; 49: 185- 8. 
9. Khan YA, Akhter J. Pneumoscrotum: A rare presentation of gastric perforation in neonate. APSP J 2010; 1 : 15.

10. Rosser SB, Clark CH, Elachi EN. Spontaneous Gastric Perforation. J Pediatr Surg 1982; 17: 390-4.

11. Byun J, Kim HY, Noh SY et al. Neonatal gastric perforation: A single centre experience. World J Gastrointestinal Surg 2014; 6(8): 151-5.

12. Grossfeld JL, Molinari F, Cheat M et al. Gastroinetstinal perforation and peritonitis in infants and children: Experience with 179 cases over ten years. Surgery 1996; 120(4): 650-6.

13. Ghribi A, Krichena I, Hassen AF et al. Gastric perforation in the newborn. La Tunisie Medicale 2013; 91(7): 464-7.

14. Shashikumar VL, Bassuk A, Pilling IV GP et al. Spontaneous gastric rupture in newborn: A clinical review of 19 cases. Ann Surg 1975; 182(1): 22-5.

15. Kella N, Surahio AR, Soomro BA et al. Gastric perforation in Newborns: Analysis of 14 cases. J Liaquat University, Med and Health Sci 2011; 10(3): 163-7.

16. Srivastava UK, Singh DP, Gupta A, Jagdeep. A report of two cases of gastric perforation in neonates. J Indian Assoc Pediatr Surg 2004; 9: 35-8.
17. Kara CS, Ilce I, Celayir $S$ et al. Neonatal Gastric Perforation; Review of 23 years experience. Surg today 2004; 34: 243-5

18. Takedo FR, Cecconello I, Szachnowicz S et al. Anatomic study of gastric vascularization and its relationship to cervical gastroplasty. J Gastrointes Surg 2005; 9: 132-7.

19. Kshirsagar AY, Vasisth GO, Ahire MD et al. Acute spontaneous gastric perforation in neonate: A report of Three cases. Afr J Pediatr Surg 2011; 8: 79-81.

20. Woo J, Eusterbrock T, Kim S. Intrauterine Gastric perforation. Pediatr Surg Int 2006; 22(10): 829-31.

21. Ohshiro K, Yamatake A, Kobayashi $\mathrm{H}$ et al. Idiopathic Gastric Perforation in neonates and abnormal distribution of intestinal pacemaker cells. J Pediatr Surg 2000; 35(5): 673-6.

22. Kumero RT, Hadley GP, Wierma R. Neonatal Gastric Perforation. East Afr Med J 2004; 8(1): 56-8.

23. Chung MT, Kuo CY, Wang JW et al. Gastric Perforation in the Neonate: clinical analysis of 12 cases. Acta Paed Sin 1994; 35(5): 460-4.

24. Miller RA. Observation on the gastric acidity during the first month of life. Arch Dis Child 1941; 16: 22-30. 